\section{Management of inflammatory corneal melt leading to central perforation in children: a retrospective study and review of literature}

A Medsinge ${ }^{1}$, E Gajdosova², W Moore $^{2}$ and KK Nischal ${ }^{1,2,3}$

\begin{abstract}
Purpose To assess the outcome of early therapeutic penetrating keratoplasty (PKP) for corneal melt leading to perforation in children.

Methods Case notes of all the consecutive patients presenting with acute corneal perforation that underwent urgent therapeutic PKP between 2000 and 2010 to the practice of one of the authors, both NHS at Great Ormond Street Hospital for Children and private, were retrospectively reviewed. Onset of perforation, underlying cause, medical and surgical treatment, pre- and post-operative visual acuity, graft clarity, length of followup, and post-operative complications were recorded.

Results Four eyes of four consecutive patients (mean age of 9.5 years and median 8.5 years, range 4-17 years) were treated for acquired acute onset corneal perforations. There were three females and one male. Etiologies included herpes simplex keratitis secondary to immune recovery disease post bone marrow transplantation, acanthamoeba keratitis, recessive dystrophic epidermolysis bullosa, and blepharokeratoconjunctivitis with acne rosacea. Pre-operative visual acuity ranged from hand movements to $6 / 150$. All the patients had severe anterior chamber inflammation. All eyes improved in visual acuity ranging from $6 / 9$ to $6 / 18$ with clear grafts at last follow-up. There was no recurrence of melt or perforation.

Mean follow-up was 67 months (median 44 months).

Conclusion PKP during the acute phase together with aggressive medical therapy and close follow-up may achieve good visual outcomes in children with corneal melt with perforation and should be considered.
\end{abstract}

Waiting may sometimes allow the marked inflammatory response seen in children to cause irreversible structural and/or functional damage.

Eye (2016) 30, 593-601; doi:10.1038/eye.2015.278; published online 29 January 2016

\section{Introduction}

Non-traumatic corneal perforation in children is rare, but may be seen in neurotrophic ulcers, ${ }^{1}$ infectious keratitis, ${ }^{2}$ peripheral ulcerative keratitis, ${ }^{3-5}$ ocular surface diseases such as blepharokeratoconjunctivitis (BKC) with or without rosacea, ${ }^{6,7}$ and chemical burns. ${ }^{8}$ Systemic conditions including juvenile rheumatoid arthritis ${ }^{9,10}$ and Stevens Johnson syndrome ${ }^{11,12}$ can rarely cause corneal perforation, while in developing countries, vitamin A deficiency is a common cause of non-infectious corneal melt in children. ${ }^{13}$

The diagnosis and treatment of corneal perforation in children is difficult, because they are often unable to communicate their symptoms clearly, have limited cooperation and many cases present late.

To complicate the issue further, children can lose vision not only from subsequent scarring but also from amblyopia.

Although the literature has reports about management of bacterial and fungal keratitis in mixed cohorts of adults and children, 2,14-18 especially in developing countries, there is little about the management of protozoal or viral keratitis and even less about non-infectious keratitis leading to perforation in children.

We present four cases of central corneal melt leading to perforation, all secondary to an inflammatory etiology (two infectious and two non-infectious) and all treated successfully with
${ }^{1}$ Department of Ophthalmology, Children's Hospital of Pittsburgh of UPMC, Pittsburgh, PA, USA

${ }^{2}$ Clinical and Academic Department of Ophthalmology, Great Ormond Street Hospital for Children, London, UK

${ }^{3}$ University of Pittsburgh School of Medicine, Pittsburgh, PA, USA

Correspondence: KK Nischal, Department of Ophthalmology, Children's Hospital of Pittsburgh of UPMC, 4401 Penn Avenue, FP 5106, Pittsburgh,

PA 15224, USA.

Tel: +1 412692 8940;

Fax: +1 4126923203 .

E-mail: nischalkk@upmc.edu

Received: 11 April 2015 Accepted in revised form: 17 November 2015 Published online: 29 January 2016 
Table 1 Demographic profile of the patients

\begin{tabular}{|c|c|c|c|c|c|c|}
\hline Case no. & $\begin{array}{l}\text { Age (years)/ } \\
\text { sex }\end{array}$ & Predisposing condition & $\begin{array}{l}\text { BCVA of the } \\
\text { affected } \\
\text { eye at } \\
\text { presentation }\end{array}$ & $\begin{array}{c}B C V A \text { of } \\
\text { the } \\
\text { affected eye } \\
\text { at last FU }\end{array}$ & $\begin{array}{c}\text { Time } \\
\text { between } \\
\text { perforation } \\
\text { and PKP }\end{array}$ & $F U(M)$ \\
\hline 1 & $4 / \mathrm{F}$ & Acanthamoeba keratitis & $\mathrm{HM}$ & $6 / 9$ & $24 \mathrm{~h}$ & $90 \mathrm{M}$ \\
\hline 2 & $17 / \mathrm{F}$ & Epidermolysis bullosa, MGD & $\mathrm{HM}$ & $6 / 9$ & 7 days & $26 \mathrm{M}$ \\
\hline 3 & $12 / \mathrm{F}$ & $\begin{array}{l}\text { MGD, Blepharokeratoconjunctivitis secondary } \\
\text { to acne rosacea }\end{array}$ & $6 / 150$ & $6 / 9$ & Less than 2 weeks & $62 \mathrm{M}$ \\
\hline 4 & $5 / \mathrm{M}$ & $\begin{array}{l}\text { HSK secondary to immune recovery disease s/p } \\
\text { BMT for severe combined immunodeficiency (SCID) }\end{array}$ & $\mathrm{HM}$ & $6 / 18$ & Less than 2 weeks & $90 \mathrm{M}$ \\
\hline
\end{tabular}

Abbreviations: M, male; F, female; MGD, Mebomian Gland Dysfunction; BCVA, best-corrected visual acuity; HM, hand movements; FU, follow-up; M, months; PKP, penetrating keratoplasty; S/p BMT, status post bone marrow transplantation; $\mathrm{ft}$, feet.

prompt and early therapeutic penetrating keratoplasty (PKP), while the eyes were still inflamed. The degree of inflammation prompted intervention as it was felt that despite anti-inflammatory therapy, damage sustained by inflammation would be too detrimental.

\section{Materials and methods}

Case notes of all consecutive patients between 2000 and 2010 with acquired corneal melt and perforation who presented to one surgeon (KKN) in a single tertiary care pediatric hospital or private office $(\mathrm{KKN})$ were retrospectively reviewed. At Great Ormond Street Hospital for Children, this study was considered to be a part of an audit and as such not considered to require ethics committee approval. Onset of perforation, underlying cause, medical and surgical treatment, pre- and post-operative visual acuity, length of follow-up, and postoperative complications were recorded. A literature review was performed using PubMed using the MeSH terms corneal melt, perforation, keratoplasty, and children.

\section{Results}

Four eyes of four patients (mean age of 9.5 years and median 8.5 years, range 4-17 years) were treated for acquired corneal perforations. There were three females and one male (see Table 1).

The onset of all corneal perforations was acute after progressive corneal melting. PKP was performed in all four eyes while the eyes were still inflamed. All the perforations were central. Two of four eyes showed an aggressive fibrinous reaction at the time of the surgery, involving the lens and necessitating lensectomy. Conservative measures such as bandage contact lens (BCL) and tissue adhesive were used before PKP in the two non-infective cases. The two patients with infective keratitis were treated medically with appropriate antimicrobial agents after microbiological workup. The two patients with non-infectious etiology received oral steroids postoperatively. All the post-operative medications are shown in Table 2. All the cases were followed up for a mean period of 67 months and median of 44 months (range 26-90 months). Cases are described in detail below. The results of the literature review are summarized in Table 3.

\section{Case 1}

A 4-year-old girl was reoffered to GOSH with a diagnosis of left eye Herpes Simplex Virus (HSV) keratitis. Corneal scrapings at the outside hospital did not grow any organisms, and she was treated empirically with topical as well as oral acyclovir and topical steroids. On presentation, her BCVA was hand movements (HM) in the left eye. Right eye was unremarkable. She responded well to the topical treatment with remarkable improvement in vision to $6 / 12$ in 2 weeks. At this stage, the steroids were tapered. Soon after tapering the steroids, the keratitis recurred with a decrease in the visual acuity to counting fingers. She was again started on intensive steroids and her improved to 6/30. Three months after her initial presentation, she developed corneal epithelial defect for which a temporal tarsorrhaphy was performed in addition to the treatment with topical and systemic acyclovir, topical steroids, chloramphenicol, and atropine eye drops. A month later, she developed corneal ulcer with hypopyon with a decrease in visual acuity to HM. Corneal scrapings performed at this stage were positive for acanthamoeba. She was started on polyhexamethylene biguanide (PHMB) and hexamidine eye drops. Two weeks later, the ulcer perforated needing an emergent PKP (Figure 1a). Postoperatively, topical steroid and antibiotic combination drops along with PHMB drops were started. She was evaluated twice a week in the in the immediate post-operative period; and the drops were tapered gradually to once a day over a period of 4 weeks and PHMB was continued for another 4 weeks. She was also continued on topical and systemic acyclovir until the confirmation of acanthamoeba in the corneal button, and 


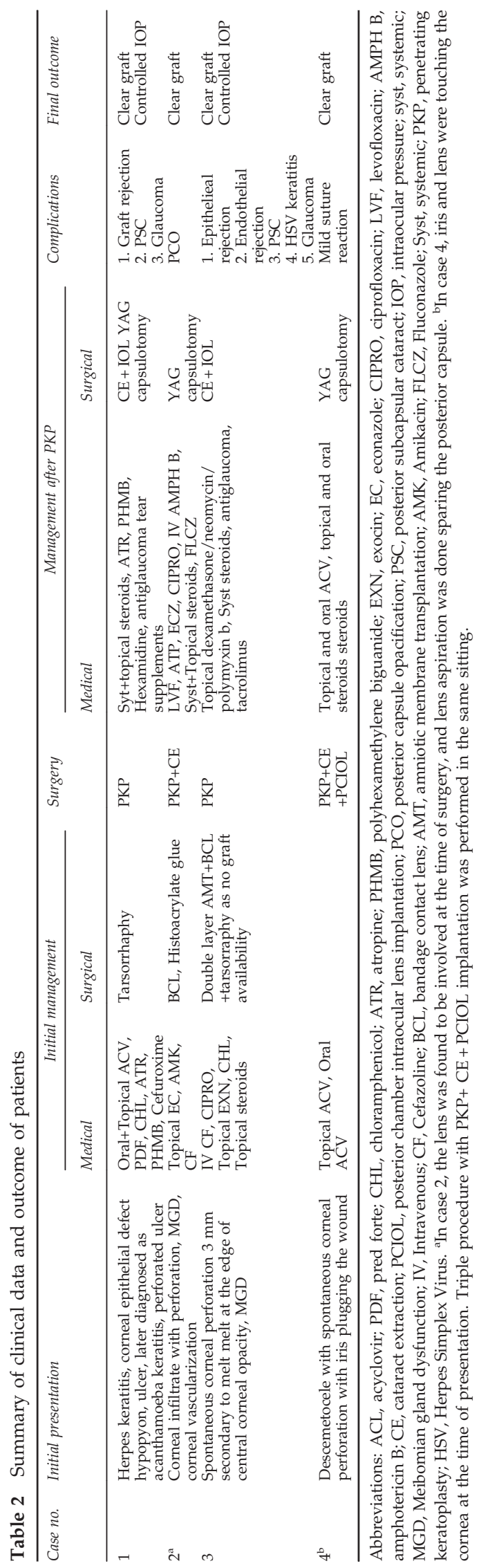

PCR was negative for HSV. One month postoperatively, she developed an increase in intraocular pressure (IOP) with endothelial rejection of the graft. IOP was controlled with topical antiglaucoma medications, and the graft rejection was treated with topical and systemic steroids ( $1 \mathrm{mg} / \mathrm{kg}$ body weight) tailored over a period of 6 weeks. At 12 months follow-up, her BCVA in the left eye was $6 / 60$ with a posterior subcapsular cataract, for which underwent cataract extraction with PCIOL implantation. Ten months after cataract extraction her BCVA improved to $6 / 24$ with $+1.5 /-6.00 \times 80^{\circ}$ with graft clear graft and controlled IOP. Four years after cataract surgery, she developed posterior capsular opacification (PCO) for which Neodymium-doped yttrium aluminum garnet (Nd-YAG) capsulotomy was performed with improvement in visual acuity to $6 / 15$. She continued to use topical steroids, lubricants, and antiglaucoma medications. Seven years after the PKP; she was again successfully treated for early endothelial graft rejection with topical steroids. At the last follow-up, 90 months after PKP, her BCVA in the left eye was 6/9, with IOP of $11 \mathrm{~mm} \mathrm{Hg}$ and clear graft (Figure 1b).

\section{Case 2}

Seventeen years old girl, a known case of recessive dystrophic epidermolysis bullosa (RDEB) with meibomian gland dysfunction (MGD), developed corneal melt in the right eye; and she was referred to GOSH from other hospital for further evaluation and management. She had a history of bilateral astigmatism with posterior blepharitis, corneal scars, and recurrent corneal epithelial erosions. At presentation, her BCVA was $\mathrm{HM}$ with $0 /-2.5 \times 10^{\circ}$ and $6 / 24$ with $0 /-2.00 \times 100^{\circ}$ in the right and left eyes, respectively. She was on preservative-free econazoal $(1 \%)$, amikacin $(2.5 \%)$, and ceftazidime $(5 \%)$ in the right eye. On exam, she was noted to have marked meibomian gland dysfunction, inflamed lid margins $4 \mathrm{~mm}$ of central corneal infiltrate with shallow anterior chamber. Corneal scrapings were negative for any growth. BCL was placed in the right eye, and all the topical treatment was continued. Next day, the anterior chamber was flat and histoacrylate glue was applied. On close follow-up, it was noted that the anterior chamber had formed but the keratitis failed to respond to the antimicrobial treatment and PKP was performed 6th day after the presentation. At the time of PKP, it was found that her lens was involved and a lens aspiration was done sparing the posterior capsule (Figures 2a and b). Her post-operative course was uneventful. She was continued on topical econazol (1\%) two hourly, and also received topical levofloxacin two hourly, preservative-free dexamethasone $1 \% 2$ hourly, atropine $1 \% 3$ times/day. Systemically, she received amphotericin B $3 \mathrm{mg} / \mathrm{kg}$ once-daily intravenously (IV) 


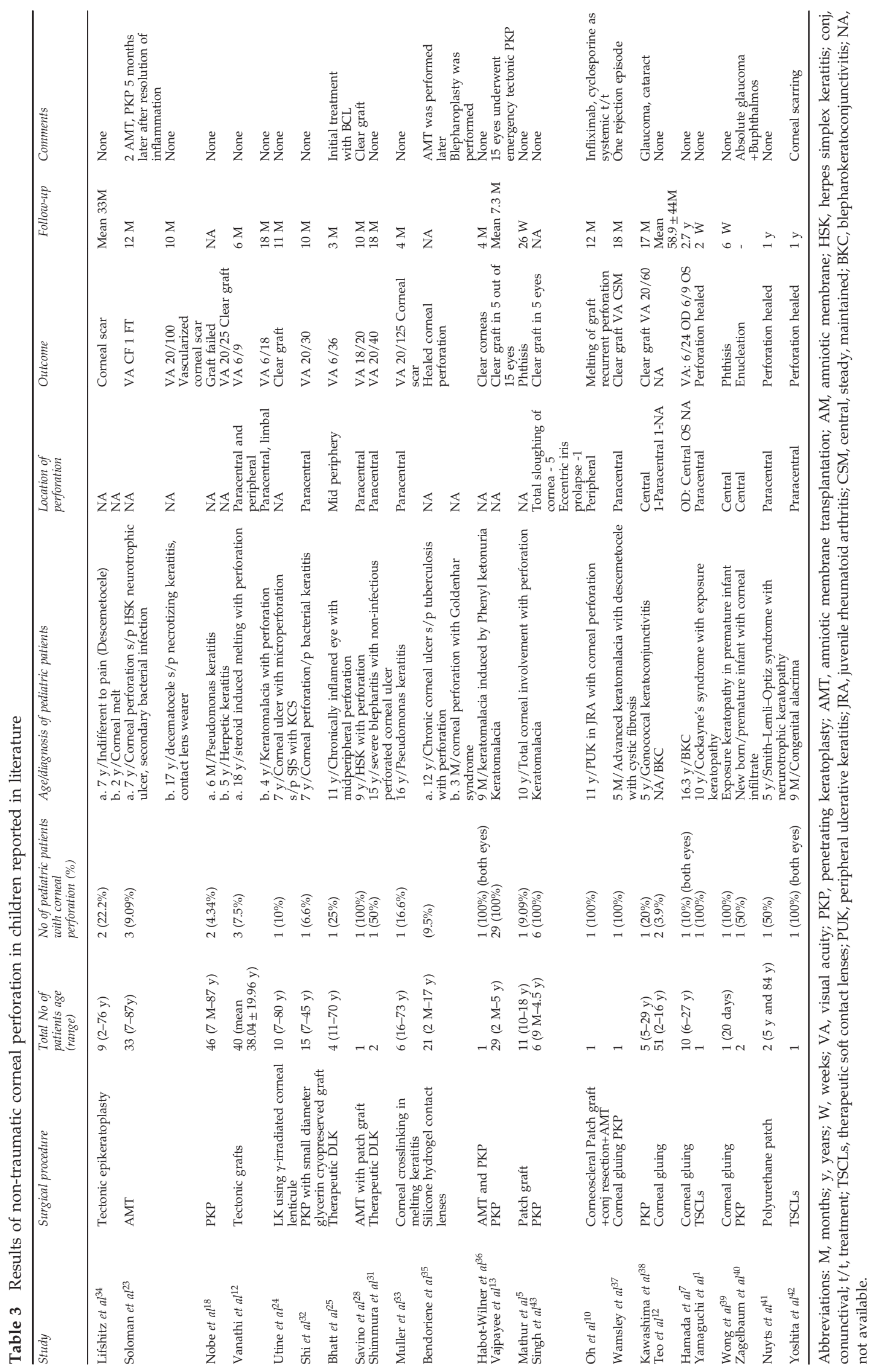




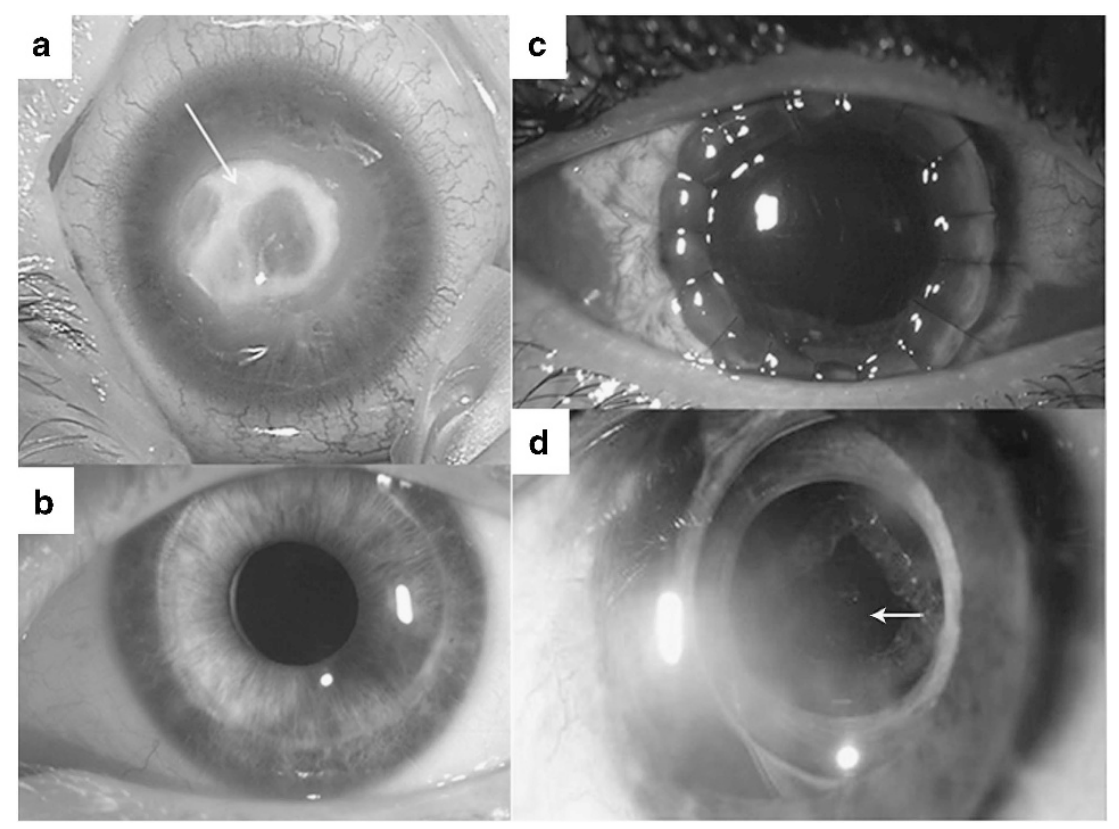

Figure 1 Pre- and post-operative pictures of case 3. (a) Case 1 with acanthamoeba keratitis: Central corneal infiltrate (long arrow) with perforation and thinning, with surrounding inflammation. The anterior chamber is almost flat (small arrow). (b) Case 1 at the last followup showing clear cornea after therapeutic penetrating keratoplasty and later cataract extraction with primary intraocular lens implantation. (c) Case 3 with Blepharokeratoconjunctivitis secondary to acne rosacea: At 1 week after therapeutic penetrating keratoplasty showing clear graft. (d) Case 3 at last follow-up showing clear visual axis and capsulotomy opening (arrow).

for 1 week, ciprofloxacin $500 \mathrm{mg}$ twice-daily for 4 days, fluconazole $300 \mathrm{mg}$ once-daily orally for days.

Histopathology of corneal button was negative for any organism as well as fungal and acanthamoeba culture. After careful discussion with microbiologists, IV methylprednisolone was started for $24 \mathrm{~h}$. Subsequently, she was put on tapering doses of oral prednisolone ( $1 \mathrm{mg} / \mathrm{kg} /$ day) over a period of 6 weeks. One week postoperatively, her BCVA was 6/60 in the right eye. At 1-year follow-up, she developed PCO and underwent Nd-YAG capsulotomy. At last follow-up, 26 months after the PKP, her BCVA in the right eye was 6/9 with IOP of $12 \mathrm{~mm} \mathrm{Hg}$ and clear graft.

\section{Case 3}

A 12-year-old girl from Namibia presented with acute right eye spontaneous corneal perforation. She was a known case of acne rosacea and MGD with a significant ocular history of bilateral pannus, left conjunctival ulcer with corneal stromal abscess and right eye corneal perforation, which was treated with conjunctival flap 1 year before her presentation to GOSH. She was otherwise healthy child, HIV negative, with a low Basal Metabolic Index, and some unspecified blood abnormality (low CD4 count). On presentation, her BCVA was 6/150 in the right eye and $6 / 9$ in the left eye. Ocular exam of the right eye showed corneal perforation ( $3 \mathrm{~mm}$ in size) secondary to melt at the edge of central cornea opacity. Left eye showed paracentral cornea scar with nasal pannus. Fundus examination of both eyes was within normal limits. She was on oral erythromycin $250 \mathrm{mg}$ QID, Exocin $3 \mathrm{~g} / \mathrm{ml}$ eye drops two hourly in the right eye and tear supplements in both eyes.

She was scheduled for PKP in the right eye, but because of the unavailability of appropriate graft material, it was decided to perform double layered amniotic membrane transplantation (AMT) with central tarsorrhaphy in the right eye. Gradually, the anterior chamber had formed and the patient underwent PKP within 7 days to clear the visual axis. Postoperatively, there was mild uveitis and raised IOP was noted in the right eye. She was given topical dexamethasone/neomycin/polymyxin combination drops 6 times/day, antiglaucoma medications, and oral steroids. Ten days postoperatively, her BCVA in the right eye was 6/38@4 m (Figure 1c).

One month later, she developed corneal erosion and subsequent epithelial rejection which was treated with topical ofloxacin/steroid combination eye drops tapered over a period of 6 weeks. Three months postoperatively, endothelial rejection was noted, which was controlled with systemic steroids ( $2 \mathrm{mg} / \mathrm{kg} /$ day) and topical steroids tapered over a period of 6 weeks and cyclosporine eye drops. Four months later, her steroids were discontinued and she was started on Tacrolimus $150 \mathrm{mg} / \mathrm{kg} /$ day. At 12 months follow-up, central graft 


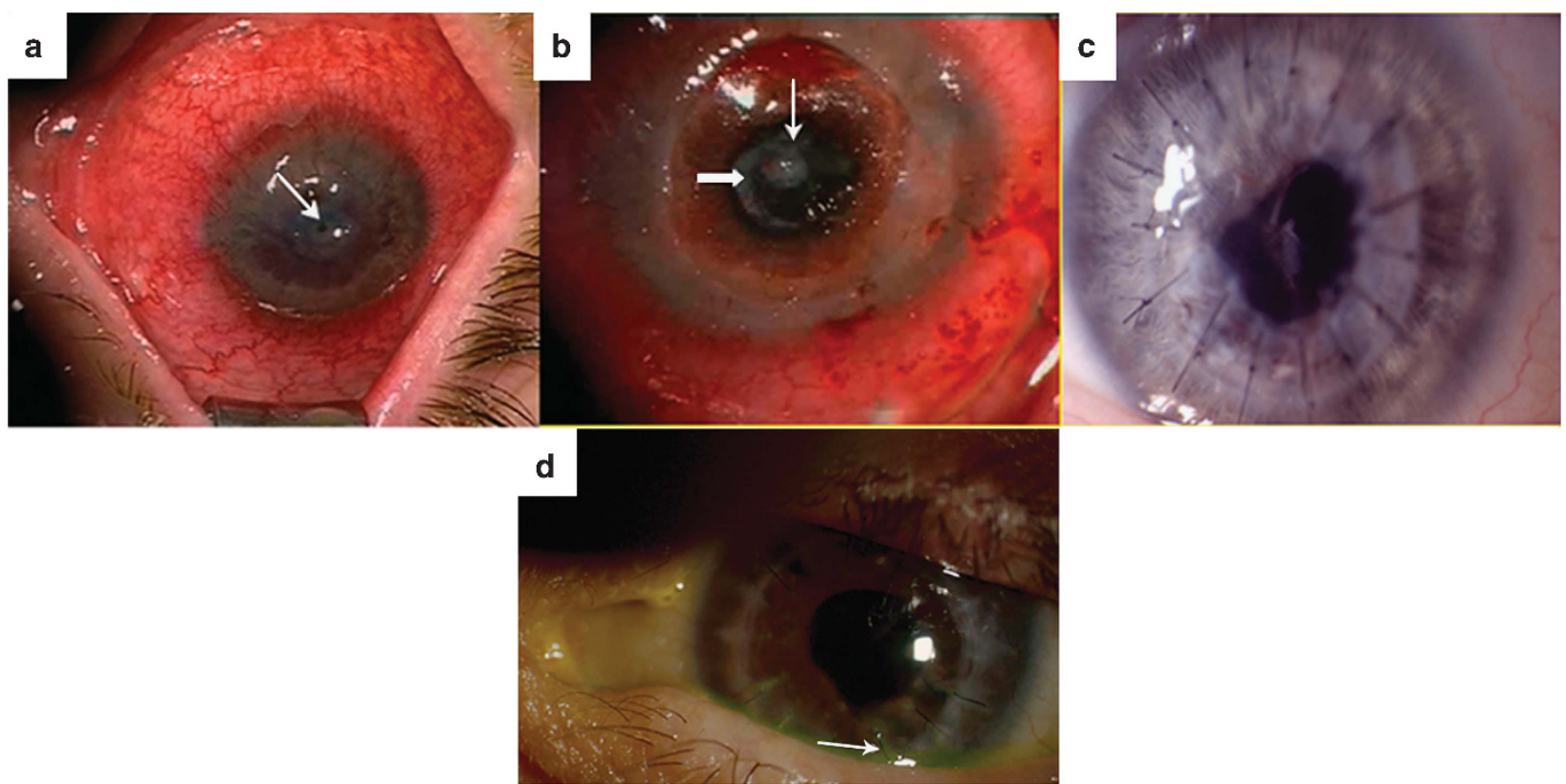

Figure 2 Pre-operative, intraoperative, and post-operative pictures of case 2 with epidermolysis Bullosa and post-operative picture of case 4. (a) Severely inflamed eye with central corneal perforation (arrow) with surrounding infiltrate and shallow anterior chamber. (b) Intraoperative still showing cataractous lens (thin arrow) and fibrin reaction (bold arrow) in the anterior chamber. (c) Clear cornea after therapeutic penetrating keratoplasty. (d) Post-op picture of case 4 with Herpes simplex keratitis secondary to immune recovery disease showing clear cornea with loose sutures (arrow).

haze was noticed along with subcapsular lens opacity in the right eye; with BCVA of 6/48. A diagnosis of herpes keratitis was made and treated with systemic and topical acyclovir. Right eye cataract progressed and a lensectomy with PCIOL was performed 26 months post PKP. Post cataract extraction and PCIOL implantation, her BCVA improved to $6 / 12$ in the right eye. She subsequently had Nd-YAG capsulotomy for the PCO in the right eye. At the last follow-up, 62 months after PKP, her BCVA in the right was 6/9 with clear graft (Figure 1d). She was on tapering doses of tacrolimus.

\section{Case 4}

A 5-year-old male child with a significant medical history of immune recovery disease $\mathrm{s} / \mathrm{p}$ bone marrow transplantation (BMT) for severe combined immunodeficiency (SCID) presented with right eye descemetocele. He was diagnosed with bilateral herpes simplex keratitis (HSK) secondary to immune recovery disease from his BMT for SCID and was taking topical and oral acyclovir. At presentation, his BCVA was $\mathrm{HM}$ in both eyes. On ocular exam, he was noted to have descemetocele in the left eye with spontaneous corneal perforation which was plugged by the iris. The lens was also touching the cornea. His right eye showed corneal scarring with ghost vessels due to previous episode of
HSK. Fundus evaluation was within normal limits in both eyes.

Because of the involvement of iris and lens, a triple procedure with $\mathrm{PKP}+\mathrm{CE}+\mathrm{PCIOL}$ implantation was performed. Postoperatively, he was continued on topical and oral acyclovir and tapering doses of topical preservative-free dexamethasone $1 \%$ eye drops. He was left on dexamethasone $1 \%$ eye drops per day and prophylactic dose of oral acyclovir. At the last follow-up, 90 months after PKP, his BCVA in the left eye was 20/60 (Figure 2d). He is reviewed by his immunologist on a regular basis.

\section{Discussion}

Inflammatory corneal melting leading to perforation may be due to infectious and non-infectious destructive conditions. ${ }^{1-4,14-19}$ Failure to diagnose and treat a perforation early can lead to further corneal damage, cataract formation, secondary glaucoma due to formation of peripheral anterior synechiae, and loss of the eye, especially if the inflammatory response is marked. ${ }^{15}$ Further, a delay in the management could result in amblyopia of the affected eye, especially when the central cornea is involved. In this small case series, an aggressive inflammation of the anterior segment was found in half of the eyes, and conservative measure including anti- 
inflammatory treatment failed to allow healing of the perforation in all the eyes.

The diagnosis and treatment of corneal melt with perforation in children is complicated due to limited cooperation and lack of detailed history from the patient. There are numerous medical and surgical options for managing corneal perforation, but surgical procedures in children are technically more difficult than adults. ${ }^{20}$ The strategy for managing corneal perforation should address the underlying process leading to keratolysis as well as the surgical aspect to restore the integrity of the globe and useful vision. It is our suggestion that the welldocumented increased inflammatory response seen in children should also have some consideration in the decision-making algorithm. We report four pediatric cases of corneal melt and perforation with uncommon etiologies. Although each etiology is rare, the case series demonstrated successful outcomes, using an aggressive paradigm of early surgical intervention. To the best of our knowledge, AK has not been previously reported in a 4-year-old child (Figures 1a and b); neither are we aware of any report on corneal perforation secondary to RDEB and HSK secondary to immune recovery disease postBMT. Perforation in BKC in a 12-year-old child is also extremely rare.

Corneal perforations not due to bacterial keratitis are rare in children. This would explain why only four cases were seen during a 10-year period. Treatment options for corneal melt and perforations include medical therapy of underlying diseases and; simple measures such as BCL, corneal gluing, and tarsorrhaphy. ${ }^{21}$ If these methods fail, then authors have described the use of conjunctival flaps, ${ }^{22}$ AMT, ${ }^{23}$ lamellar keratoplasty (LK), ${ }^{24}$ deep lamellar keratoplasty (DLK), ${ }^{25}$ patch graft, ${ }^{12}$ or PKP. ${ }^{18,19}$

Tissue adhesives can be used to close small perforation (up to $3 \mathrm{~mm}$ in diameter) and may slow down stromal melting. ${ }^{21,26}$ Although Leahey et $a l^{21}$ in a series of 44 patients ( 3 children) used cyanoacrylate glue to treat perforations, 2 children needed a subsequent conjunctival flap and PKP, resulting in poor visual outcome (see Table 3). We used histoacrylate glue and BCL in case 2 (Figure 2a), but the aggressive inflammatory reaction with a non-healing perforation prompted a therapeutic PKP immediately (Figures $2 \mathrm{~b}$ and $\mathrm{c}$ ).

Although conjunctival flaps have been used in corneal perforations, as a temporary measure in an inflamed eye, they often result in a vascularized cornea scar. All our cases had central corneal perforation which would have resulted in central scar if we had used conjunctival flaps, with subsequent likely deprivation amblyopia.

Although AMT has also been employed in patients with corneal perforations in cases with central corneal perforation, published data suggest poor visual outcome with PKP being needed later almost invariably (see Table 3). ${ }^{23,27}$

In the only report of good visual outcome using simultaneous patch graft and AMT in a 9-year-old girl, the perforation was midperipheral and not central. ${ }^{28}$ In our series case 3, with acne rosacea, AMT was utilized to treat the central corneal perforation purely because the appropriate graft material was not available. After the formation of anterior chamber, PKP was performed within 7 days to clear the optical axis (Figures 1c and d).

Historically, therapeutic PKP has been discouraged in inflamed perforated eye because of increased complication rates and poor visual outcomes. ${ }^{29}$ In this series, it was the senior surgeon's assessment that in at least two of four cases secondary inflammation was thought potentially to be irreversibly damaging.

Therapeutic PKP in inflamed eyes with corneal perforation secondary to microbial keratitis (especially bacterial and fungal) is well described in developing countries. ${ }^{16,17}$ In one such series of 46 eyes of 46 patients, only 2 were children and both had therapeutic PKP; 1 child had a failed PKP but was 6 months old and another child (5 years old) had successful PKP after initial glue for perforation due to HSK. ${ }^{18}$ In one of the largest pediatric specific series of microbial keratitis, only 2 patients out of 78 presented with perforation. ${ }^{30}$

Other techniques described to treat corneal perforations include LK or DLK, PKP with glycerin cryopreserved grafts and most recently crosslinking. ${ }^{24,25,31-33}$ All these have limited experience in children.

It is apparent that perforation of cornea in developed countries is rare. This is reflected by the unique etiology in 3 of 4 cases namely AK in a 4-year-old child, RDEB, HSK secondary to immune recovery disease post bone marrow transplantation and BKC secondary to acne rosacea. All our cases had central corneal perforation and either showed failure to heal and/or had aggressive anterior chamber inflammation. Therapeutic PKP even during an inflamed stage resulted in visual outcome that varied from $6 / 9$ to $6 / 18$.

In two of our patients (cases 1 and 3), the post-operative course was complicated by increased IOP and graft rejection which were managed successfully medically. These two patients also developed posterior subcapsular lens opacity and underwent cataract extraction with intraocular lens implantation. In two cases (2 and 4), the lens was found to be involved at the time of surgery and lens aspiration was done sparing the posterior capsule (Figure 2d). Three patients (cases 1-3) subsequently developed posterior capsule opacification and underwent YAG capsulotomies. Despite the complicated postoperative course, the final visual outcome was good. All four patients had lens removal either subsequent to 
PKP or at the time of PKP. Three had an IOL and one remained aphakic (patient with RDEB).

We conclude that while published reports describe poor outcomes generally in children with corneal perforation, this may be because the increased intraocular inflammation known to occur in children may have been overlooked. We suggest therapeutic intervention during the inflamed stage even for non-infectious cases should be considered.

\section{Summary}

What was known before

- Inflammatory cornea melt leading perforation is rare in children.

- The outcomes are generally poor.

- Penetrating keratoplasty for acute corneal perforation in an inflamed eye has rarely been performed in children.

- The literature does not describe this mode of management especially in children.

What this study adds

- This study shows that penetrating keratoplasty (PKP) during the acute phase together with aggressive medical therapy and close follow-up may achieve good visual outcomes in children with corneal melt.

- This study suggests that therapeutic intervention in the form of PKP during the inflamed stage even for noninfectious cases should be considered in children.

\section{Conflict of interest}

The authors declare no conflict of interest.

\section{References}

1 Yamaguchi K, Okabe H, Tamai M. Corneal perforation in a patient with Cockayne's syndrome. Cornea 1991; 10: 79-80.

2 Zaidman GW. The pediatric corneal infiltrate. Curr Opin Ophthalmol 2011; 22: 261-266.

3 Leung AK, MireskandariK, Ali A. Peripheral ulcerative keratitis in a child. J AAPOS 2011; 15: 486-488.

4 Agarwal P, Singh D, Sinha G, Sharma N, Titiyal JS. Bilateral Mooren's ulcer in a child secondary to helminthic infestation of the gastrointestinal tract. Int Ophthalmol 2012; 32: 463-466.

5 Mathur A, Ashar J, Sangwan VS. Mooren's ulcer in children. Br J Ophthalmol 2012; 96: 796-800.

6 Teo L, Mehta JS, Htoon HM, Tan DT. Severity of pediatric blepharokeratoconjunctivitis in asian eyes. Am J Ophthalmol 2012; 153: 564-570.

7 Hamada S, Khan I, Denniston AK, Rauz S. Childhood blepharokeratoconjunctivitis: characterizing a severe phenotype in white adolescents. Br J Ophthalmol 2012; 96: 949-955.

8 Pfister RR. Chemical injuries of the eye. Ophthalmology 1983; 90: 1246-1253.

9 Papathanassiou M, Zampeli E, Kaplanoglou T, Theodossiadis P. Peripheral ulcerative keratitis in a patient with systemic-onset juvenile idiopathic arthritis. J Pediatr Ophthalmol Strabismus 2010; 47: e1-e3.

10 Oh JY, Kim MK, Wee WR. Infliximab for progressive peripheral ulcerative keratitis in a patient with juvenile rheumatoid arthritis. Jpn J Ophthalmol 2011; 55: 70-71.

11 Shammas MC, Lai EC, Sarkar JS, Yang J, Starr CE, Sippel KC. Management of acute Stevens-Johnson syndrome and toxic epidermal necrolysis utilizing amniotic membrane and topical corticosteroids. Am J Ophthalmol 2010; 149: 203-213.

12 Vanathi M, Sharma N, Titiyal JS, Tandon R, Vajpayee RB. Tectonic grafts for corneal thinning and perforations. Cornea 2002; 21: 792-797.

13 Vajpayee RB, Vanathi M, Tandon R, Sharma N, Titiyal JS. Keratoplasty for keratomalacia in preschool children. Br J Ophthalmol 2003; 87: 538-542.

14 Portnoy SL, Insler MS, Kaufman HE. Surgical management of corneal ulceration and perforation. Surv Ophthalmol 1989; 34: 47-58.

15 Lekskul M, Fracht HU, Cohen EJ, Rapuano CJ, Laibson PR. Nontraumatic corneal perforation. Cornea 2000; 19: 313-319.

16 Titiyal JS, Negi S, Anand A, Tandon R, Sharma N, Vajpayee RB. Risk factors for perforation in microbial corneal ulcers in north India. Br J Ophthalmol 2006; 90: 686-689.

17 Moorthy S, Jhanji V, Constantinou M, Beltz J, Graue-Hernandez EO, Vajpayee RB. Clinical experience with N-butyl cyanoacrylate tissue adhesive in corneal perforations secondary to herpetic keratitis. Cornea 2010; 29: 971-975.

18 Nobe JR, Moura BT, Robin JB, Smith RE. Results of penetrating keratoplasty for the treatment of corneal perforations. Arch Ophthalmol 1990; 108: 939-941.

19 Jhanji V, Young AL, Mehta JS, Sharma N, Agarwal T, Vajpayee RB. Management of corneal perforation. Surv Ophthalmol 2011; 56: 522-538.

20 Vanathi M, Panda A, Vengayil S, Chaudhuri Z, Dada T. Pediatric keratoplasty. Surv Ophthalmol 2009; 54: 245-271.

21 Leahey AB, Gottsch JD, Stark WJ. Clinical experiences with nbutyl cyanoacrylate tissue adhesive. Ophthalmology 1993; 100(2): 173-180.

22 Khodadoust A, Quinter P. Microsurgical approach to conjunctival flap. Arch Ophthalmol 2003; 121: 1189-1193.

23 Soloman A, Meller D, Prabhasawat P, John T, Espana EM, Steuhl KP et al. Amniotic membrane grafts for nontraumatic corneal perforations, descemetoceles and deep ulcers. Ophthalmology 2002; 109: 694-703.

24 Utine CA, Tzu JH, Akpek EK. Lamellar keratoplasty using gamma-irradiated corneal lenticules. Am J Ophthalmol 2011; 151: 170-174.

25 Bhatt PR, Lim LT, Ramaesh K. Therapeutic deep lamellar keratoplasty for corneal perforations. Eye (Lond) 2007; 21(9): 1168-1173.

26 Fogle JA, Kenyon KR, Foster CS. Tissue adhesive arrests stromal melting in the human cornea. Am J Ophthalmol 1980; 89: 795-802.

27 Prabhasawat P, Tesavibul N, Komolsuradej W. Single and multilayer amniotic membrane transplantation for persistent corneal epithelial defect with and without stromal thinning and perforation. Br J Ophthalmol 2001; 85: 1455-1463.

28 Savino G, Colucci D, Giannico MI, Salgarello T. Amniotic membrane transplantation associated with a corneal patch in a pediatric corneal perforation. Acta Ophthalmol 2010; 88: e15-e16. 
29 Dohlman CH, Boruchoff SA, Sullivan GL. A technique for the repair of perforated corneal ulcers. Arch Ophthalmol 1967; 77: 519-525.

30 Hsiao CH, Yeung L, Ma DH, Chen YF, Lin HC, Tan HY et al. Pediatric microbial keratitis in Taiwanese children. a review of hospital cases. Arch Ophthalmol 2007; 125: 603-609.

31 Shimmura S, Shimazaki J, Tsubota K. Therapeutic deep lamellar keratoplasty for cornea perforation. Am J Ophthalmol 2003; 135: 896-897.

32 Shi W, Liu M, Gao H, Li S, Wang T, Xie L. Penetrating keratoplasty with small-diameter and glycerincryopreserved grafts for eccentric corneal perforation. Cornea 2009; 28: 631-637.

33 Müller L, Thiel MA, Kipfer-Kauer AI, Kaufmann C. Corneal cross-linking as supplementary treatment option in melting keratitis: a case series. Klin Monbl Augenheilkd 2012; 229: 411-415.

34 Lifshitz T, Oshry T. Tectonic epikeratoplasty: a surgical procedure for corneal melting. Ophthalmic Surg Lasers 2001; 32: 305-307.

35 Bendoriene J, Vogt U. Therapeutic use of silicone hydrogel contact lenses in children. Eye Contact Lens 2006; 32: 104-108.

36 Habot-Wilner Z, Spierer A, Barequet IS, Greenbaum A. Use of amniotic membrane graft and corneal transplantation in a patient with bilateral keratomalacia induced by uncontrolled phenylketonuria. Cornea 2007; 26: 629-631.

37 Wamsley S, Patel S, Wood MG, Villalobos R, Albert DM, Mootha VV et al. Advanced keratomalcia with descemetocele in an infant with cystic fibrosis. Arch Ophthalmol 2005; 123: 1012-1016.

38 Kawashima M, Kawakita T, Den S, Tomita M, Shimazaki J. Surgical management of corneal perforation secondary to gonococcal keratoconjunctivitis. Eye (Lond) 2009; 23: 339-344.

39 Wong JS, Balakrishnan V, Tan KL. Spontaneous corneal perforation in premature infants. Singapore Med J 1997; 38: 469-470.

40 Zagelbaum BM, Stroh EM, Perry HD, Donnenfeld ED, Cossari AJ. Corneal perforation in a premature infant. J Refract Surg 1995; 11: 96-98.

41 Nuyts RM, Kooijman-DeGroot MJ, Prins M, Pels E. Use of a polyurethane patch for temporary closure of a sterile corneal perforation. Arch Ophthalmol 1999; 117: 1427-1429.

42 Yoshita T, Kobayashi A, Sugiyama K. Bilateral corneal perforation in an infant with congenital alacrima. J Pediatr Ophthalmol Strabismus 2006; 43(4): 236-238.

43 Singh G, Malik SR. Therapeutic penetrating keratoplasty in keratomalcia. Br J Ophthalmol 1973; 57: 638-640. 